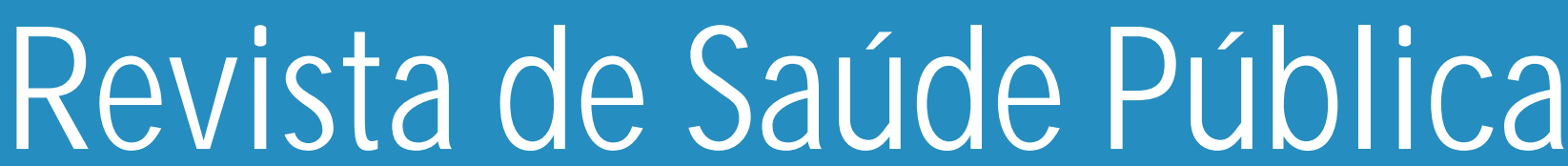

Journal of Public Health

Artigo Especial

Special Article

\title{
Requisitos uniformes para manuscritos apresentados a periódicos biomédicos*
}

U niform requirements for manuscripts submitted to biomedical journals

International Committee of Medical Journal Editors** 


\title{
Requisitos uniformes para manuscritos apresentados a periódicos biomédicos* U niform requirements for manuscripts submitted to biomedical journals
}

\author{
International Committee of Medical Journal Editors**
}

Um pequeno grupo de editores de periódicos médicos gerais encontraram-se informalmente em Vancouver, Canadá, em 1978, para estabelecer diretrizes para a normalização de manuscritos apresentados às suas revistas. O grupo tornou-se conhecido como "Grupo de Vancouver".

Seus Requisitos Uniformes para Manuscritos, incluindo as normas para referências bibliográficas desenvolvidas pela National Library of Medicine (NLM), dos Estados Unidos, foram publicadas inicialmente em 1979. O Grupo de Vancouver expandiuse e evoluiu para converter-se na Comissão Internacional de Editores de Revistas Médicas, que se reúne anualmente, ampliando gradualmente os temas estudados. A Comissão produziu 5 edições dos Requisitos Uniformes para Manuscritos apresentados a Periódicos Biomédicos. Ao longo dos anos, apareceram aspectos que foram além do mero preparo de manuscritos. Alguns desses aspectos estão agora incorporados aos Requisitos Uniformes; outros estão publicados em separado, em revistas médicas. A $5^{\text {a }}$ edição (1997) é um esforço para reorganizar e reescrever a $4^{\mathrm{a}}$ edição com o intuito de esclarecer e direcionar interesses sobre direitos, privacidade, descrição de métodos e outros assuntos. O conteúdo integral dos Requisitos Uniformes pode ser reproduzido para propósitos educacionais e sem fins lucrativos, fazendo menção aos direitos autorais; a comissão encoraja a distribuição do material. Às revistas que adotam os Requisitos Uniformes (acima de 500 o fazem) é solicitado que citem o documento de 1997 em suas instruções aos autores.

É importante enfatizar o que significam estas normas. Primeiro, os Requisitos Uniformes são instruções aos autores de como preparar manuscritos, mas não são um manual de estilo para editores. (No entanto, muitas revistas os têm adotado para questões de estilo de suas publicações).

Segundo, se os autores preparam seus trabalhos de acordo com o estilo especificado nestes requisitos, os editores das revistas participantes comprometem-se a não retornar os manuscritos para mudanças no estilo antes de considerá-lo para publicação. No entanto, durante o processo de publicação, as revistas podem alterar os manuscritos com o objetivo de adequá-los a certos aspectos de seu próprio estilo.

Terceiro, os autores que enviam manuscritos a uma revista participante deverão seguir os Requisitos Uniformes. Todavia deverão respeitar as instruções aos autores no que se refere às particularidades da mesma e aos tipos de artigos que podem ser apresentados: por exemplo, artigos originais, revisões, ou relatos de casos. Além disso, é provável que as instruções das revistas contenham outros requisitos específicos tais como número de cópias exigidas para o manuscrito, idiomas aceitos, tamanho dos artigos e abreviaturas admitidas.

Espera-se que as revistas participantes esclareçam em suas instruções aos autores, que estas estão de acordo com os Requisitos Uniformes para Manuscritos

\footnotetext{
* Tradução em português do documento: International Committee of Medical Journal Editors. Uniform requirements for manuscripts submitted to biomedical journals. New Engl J Med 1997; 336: 309-16. Tradução elaborada por Ana Maria Barone, e aprovada pelo Conselho de Editores.

** Os nomes do "Committee" são: Linda Clever (West Journal of Medicine), Lois Ann Colainni (Index Medicus), Frank Davidoff (Annals of Internal Medicine), Richard Horton (Lancet), Jerome P. Kassirer and Marcia Angell (New England Journal of Medicine), George D. Lundberg and Richard Glass (Journal of the American Medical Association), Magne Nylenna (Tidsskrift for den Norske Laegeforenig), Richard G. Robinson (New Zealand Medical Journal), Richard Smith (British Medical Journal), Bruce P. Squires (Canadian Medical Association Journal), and Martin Van Der Weyden (Medical Journal of Australia).
} 
Apresentados a Periódicos Biomédicos e que citem a versão publicada dos mesmos.

\section{ÍTENS A SEREM CONSID ERAD OS ANTES DA APRESENTAÇÃO DE UM MANU SCRITO}

\section{Publicação Prévia ou Duplicada}

Publicação prévia ou duplicada é a publicação de um artigo que coincide substancialmente com outro já publicado.

Leitores de periódicos primários precisam acreditar que estão lendo um artigo inédito, a menos que seja esclarecido que o artigo voltou a ser publicado por vontade do autor e do editor. Os fundamentos desta postura são encontrados nas leis internacionais sobre direitos autorais, na ética profissional e no custobenefício quanto ao uso de recursos.

Muitas revistas não desejam receber trabalhos que já tenham sido comentados extensamente em um artigo já publicado ou que sejam parte de artigo submetido ou aceito para publicação em qualquer outro meio, seja impresso ou eletrônico. Esta política não impede que uma revista considere um artigo que tenha sido rejeitado por outro periódico ou um relatório completo resultante de uma publicação preliminar como, por exemplo, um resumo ou poster apresentado em uma reunião científica. Tampouco impede as revistas de considerarem um trabalho apresentado em uma reunião científica, mas não publicado integralmente, ou que esteja sendo publicado em anais ou formatos similares.

O autor sempre que submeter um trabalho deverá informar o editor acerca de qualquer apresentação anterior que possa ser considerada como publicações prévias ou duplicadas, do mesmo trabalho ou de algum outro que seja muito semelhante. $\mathrm{O}$ autor deve alertar se o trabalho inclui aspectos que já foram publicados previamente. Neste caso, o trabalho deverá ser mencionado e referenciado no novo artigo. Cópias do material publicado deverão ser incluídas quando o manuscrito for submetido para auxiliar o editor a decidir como tratar o assunto.

Os autores devem esperar por medidas que poderão ser tomadas pelos editores se publicações prévias ou duplicadas forem propostas sem tal informação. No mínimo, podem esperar pela rejeição do manuscrito enviado. Se o editor não for cientificado sobre a infração e o artigo for publicado, é bastante provável que se publique uma notícia de publicação prévia ou duplicada, com ou sem o consentimento do autor.

A divulgação preliminar, nos meios públicos de comunicação de massa, de informação científica contida em um artigo que foi aceito, mas ainda não publicado, viola a política de muitas revistas. Em poucos casos, e só mediante acordo prévio com o editor, aceita-se a publicação preliminar de dados, como por exemplo, em casos de emergência em saúde pública.

\section{Aceitação de uma Segunda Publicação}

Uma segunda publicação no mesmo idioma que a primeira ou em outra língua, especialmente se for realizada em outros países, é justificável e pode ser benéfica, contanto que as seguintes condições estejam presentes:

1. Os autores tenham recebido aprovação dos editores de ambas as revistas; o editor da segunda publicação tenha recebido uma fotocópia, reimpressão ou manuscrito da primeira versão.

2. Seja respeitada a prioridade da primeira publicação por um intervalo, no mínimo, de uma semana entre ambas as publicações (a menos que seja negociada de outra forma pelos dois editores). Os autores tenham recebido aprovação dos editores de ambas as revistas; o editor da segunda.

3. O artigo para a segunda publicação esteja direcionado para um grupo diferente de leitores; neste caso poderá ser suficiente uma versão abreviada.

4. A segunda versão refletir fielmente os dados e interpretações da primeira versão.

5. Uma nota de rodapé na primeira página da segunda versão deverá informar aos leitores, pesquisadores e centros de documentação que o artigo foi publicado integralmente ou em parte e apresentar a referência da primeira publicação. Uma nota de rodapé adequada deve conter: "Este artigo está baseado em estudo preliminarmente publicado em (título da revista com referência completa)".

\section{Proteção dos Direitos e Privacidade dos Pacientes que Participam de Pesquisas}

Os pacientes têm direito à privacidade, $\mathrm{o}$ que não deve ser infringido sem seu consentimento, por escrito. Informações que possam identificar uma pessoa que participou de uma pesquisa não devem ser publicadas na forma de descrições, fotografias, nem genealogias, a menos que a informação seja 
essencial para os propósitos científicos e o paciente (ou parentes ou responsáveis) dê permissão, por escrito, para a publicação.

O consentimento, por escrito, para estes propósitos exige que se mostre o manuscrito a ser publicado ao paciente.

Detalhes que sirvam para identificar as pessoas devem ser omitidos se não forem essenciais, mas os dados do paciente não devem nunca ser alterados ou falsificados, numa tentativa de procurar o anonimato. O anonimato completo é difícil de ser conseguido, assim o consentimento, por escrito, deve ser solicitado se persistir alguma dúvida. Por exemplo, encobrir a região dos olhos em fotografias de pacientes é insuficiente para manter o anonimato.

Os requisitos para o consentimento, por escrito, podem ser incluídos na revista nas instruções aos autores. No artigo publicado deverá constar que se obteve o consentimento.

\section{REQ U ISITO S PARA APRESEN TAÇÃO DE MANU SCRITOS}

\section{Resumo dos Requisitos Técnicos}

- Espaço duplo em todas as partes do manuscrito.

- Começar cada seção em uma nova página.

- Sequiência a ser seguida: página de identificação, resumo e descritores, texto, agradecimentos, bibliografia, tabelas (cada uma em páginas separadas) e legendas.

- Ilustrações (desenhos ou fotos soltas, sem montar) não devem ter mais que 203 x 254mm.

- Incluir permissão para reproduzir material previamente publicado ou para fazer uso de ilustrações que possam servir para identificar pessoas.

- Enviar documento de cessão dos direitos autorais e outros documentos que sejam necessários para a publicação.

- Apresentar o número exigido de cópias para o manuscrito.

- Guardar cópia de todo material enviado à revista.

\section{PREPARAÇÃO DO MANUSCRITO}

O texto de trabalhos de observação ou experimentais são usualmente, mas não de forma obrigatória, divididos em seções com os seguintes cabeçalhos: Introdução, Métodos, Resultados e
Discussão. Artigos longos podem incluir subcabeçalhos em algumas seções, especialmente nas de Resultados e Discussão, para esclarecer seu conteúdo. Outros tipos de artigos, tais como relatos de casos, revisões e editoriais, necessitam de outros formatos. Os autores podem consultar as instruções de outras revistas para obterem mais informações.

Após digitação, imprimir o manuscrito em papel sulfite branco de qualidade, de 216 X $279 \mathrm{~mm}$, ou ISO A4 (212 X 297mm), com margem no mínimo de $25 \mathrm{~mm}$. Imprimir em uma só face do papel, usando espaço duplo em todo o texto, incluindo a página de identificação, resumo, texto, agradecimentos, referências, tabelas e legendas. Numerar consecutivamente as páginas, começando pela página de identificação. Colocar o número da página no canto superior ou inferior direito de cada página.

\section{Manuscritos em Disquetes}

Para artigos que estão em vias de serem aceitos para publicação, algumas revistas solicitam aos autores que forneçam uma cópia em formato eletrônico (em disquete); admite-se uma grande variedade de processadores de texto ou arquivos (ASCII) (American Standard Code for Information Interchange).

Ao fornecerem os disquetes, os autores devem:

1. Incluir uma cópia impressa da versão do artigo que está no disquete;

2. Gravar somente a última versão do manuscrito no disquete;

3. Identificar claramente o arquivo;

4. Etiquetar o disquete com o formato e nome do arquivo;

5. Fornecer informações sobre o equipamento e programa usados.

Os autores devem consultar as instruções aos autores quanto aos formatos aceitos, convenções para identificar os arquivos, número de cópias a serem apresentadas e outros detalhes.

\section{Página de Identificação}

Nesta página devem constar:

1. Título do artigo, que deve ser conciso, porém informativo;

2. Nome pelo qual o autor é conhecido, com seu maior grau acadêmico e afiliação institucional;

3. Nome do departamento e instituição aos quais o trabalho deve ser atribuído; 
4. Nome e endereço do autor responsável para correspondência relativa ao manuscrito;

5. Nome e endereço do autor a quem devem ser dirigidos pedidos de separatas ou a informação de que não há separatas disponíveis;

6. Fontes de auxílio na forma de bolsas, equipamentos e outros;

7. Título abreviado do trabalho, com não mais de 40 caracteres (contando letras e espaços) no rodapé da página de identificação.

\section{Autoria}

Todas as pessoas designadas como autores devem estar qualificadas para tal. Cada autor deve ter participado suficientemente do trabalho para ter responsabilidade pública pelo seu conteúdo.

O reconhecimento da autoria deve estar baseado em contribuição substancial relacionada aos seguintes aspectos:
1. Concepção e projeto ou análise e interpretação dos dados;

2. Redação do artigo ou revisão crítica relevante do conteúdo intelectual;

3. Aprovação final da versão a ser publicada. Estas condições devem ser integralmente consideradas.

Apenas participação na aquisição de fundos, coleta de dados ou supervisão geral do grupo de pesquisa não são suficientes para justificar a autoria.

Qualquer parte do artigo que seja essencial para as conclusões fundamentais do mesmo deve ser de responsabilidade de pelo menos um autor. Os editores podem solicitar aos autores para descrever qual foi a contribuição de cada um; esta informação pode ser publicada.

Freqüentemente, os trabalhos multicêntricos são atribuídos a um autor coletivo. Todos os membros da equipe identificados como autores, seja na posição de autor indicado abaixo do título do trabalho ou em nota de rodapé, devem obedecer inteiramente aos critérios acima indicados para serem identificados como autores. Os membros da equipe que não se encaixarem nestes critérios podem figurar, com sua permissão, na seção de agradecimentos ou em um anexo (Consultar a seção "Agradecimentos”).

A ordem em que aparecem os autores deve ser resultante de uma decisão conjunta com os coautores. Como a ordem é determinada em diferentes formas, seu significado não pode ser inferido com exatidão, a menos que seja estabelecida pelos autores, que também podem explicá-la em nota de rodapé. Decidida a ordem, os autores devem estar cientes de que muitas revistas limitam o número de autores listados no índice e que a National Library of Medicine, dos Estados Unidos, só ingressam no MEDLINE os primeiros 24 autores.

\section{Resumo e Descritores}

A segunda página do manuscrito deverá conter um resumo (de não mais que 150 palavras se não for estruturado ou 250 palavras se for estruturado). O resumo deverá conter os objetivos do estudo ou pesquisa, procedimentos básicos (seleção dos indivíduos do estudo ou animais de laboratório, métodos de observação e analíticos, principais resultados apresentando dados específicos e seu significado estatístico, se possível), e as conclusões principais. Deverão ser destacados os novos e mais importantes aspectos do estudo.

Abaixo do resumo, os autores devem especificar e identificar como tal, de 3 a 10 descritores ou frases curtas que auxiliarão a indexação dos artigos nas bases de dados. Estes descritores poderão ser publicados com o resumo, podendo ser utilizados descritores do Medical Subject Headings (MESH) do Index Medicus. Se não existirem descritores apropriados disponíveis no MESH para os termos recentemente introduzidos, poderão ser utilizados termos ou expressões de uso conhecido.

\section{Introdução}

Deve conter o objetivo do artigo e resumir os fundamentos lógicos para a realização do mesmo. Apresentar somente as referências estritamente pertinentes e não incluir dados ou conclusões do trabalho que está sendo relatado.

\section{Métodos}

Descreve claramente a seleção dos indivíduos que intervieram na pesquisa (pacientes ou animais de laboratório, incluindo os controles). Identifica a idade, sexo e outras características relevantes dos indivíduos. Adefinição e relevância da raça ou etnia são ambíguas; os autores devem ser especialmente cuidadosos quando usarem estas categorias.

Os métodos, os equipamentos (apresentar o nome e endereço do fabricante entre parênteses) e os procedimentos utilizados devem ser identificados com detalhes suficientes para permitir a replicação da pesquisa por outros profissionais. Apresentar as 
referências sobre os métodos, inclusive de métodos estatísticos (veja mais adiante) e oferecer referências e breve descrição para os métodos já publicados, mas não muito conhecidos; descrever os métodos novos ou substancialmente modificados dando as razões para utilizá-los, avaliando suas limitações. Identificar com precisão todos os fármacos e produtos químicos usados, incluindo nome genérico, dosagem, e vias de administração. Informações sobre ensaios clínicos realizados de forma aleatória devem apresentar informação referente aos principais elementos do estudo, incluindo o protocolo (população do estudo, intervenções ou exposições, resultados e os fundamentos lógicos para a realização da análise estatística) e designação das intervenções (métodos de estudos randômicos, indicação dos grupos de intervenção e controle) e métodos duplamente cegos.

Os autores que apresentam revisões devem incluir uma seção que descreva os métodos empregados para localizar, selecionar, obter e sintetizar as informações. Estes métodos também devem ser apresentados sucintamente no resumo.

\section{Ética}

Quando se trata de experimentos com seres humanos, deve ser esclarecido se os procedimentos empregados respeitaram os critérios éticos da comissão sobre experimentação humana (institucional ou regional) e a Declaração de Helsinki de 1975, com emenda de 1983. Não usar os nomes dos pacientes, suas iniciais, número que lhes foi conferido no hospital, especialmente no material ilustrativo. Quando se trata de experimentação com animais, indicar se foram seguidas as recomendações, sobre o cuidado e utilização dos animais de laboratório, de alguma instituição.

\section{Estatística}

Descrever os métodos estatísticos com detalhe suficiente para permitir aos leitores, conhecedores do assunto e com acesso aos dados originais, verificar os resultados alcançados. Sempre que for possível, quantificar e apresentar os resultados com indicadores apropriados de margem de erros ou de confiabilidades (como por exemplo os intervalos de confiança). Evitar apoiar-se unicamente nas hipóteses estatísticas, tais como o uso de valores $\mathrm{P}$, uma vez que omite informação quantitativa importante.

Justificar a escolha dos indivíduos objeto da pesquisa, detalhar o método aleatório, informar sobre as possíveis complicações relacionadas ao tratamento, apresentar o número de observações e perda de indivíduos participantes (tais como desistências em um ensaio clínico). Sempre que for possível, as referências sobre o planejamento do estudo e métodos estatísticos deverão ser de trabalhos vigentes ao invés dos originais onde foram descritos pela primeira vez.

Indicar também se foram utilizados programas de computador e quais.

Incluir na seção de Métodos uma descrição geral dos métodos empregados. Quando os dados forem resumidos na seção Resultados, especificar o método estatístico usado para analisá-los. Restringir tabelas e figuras a apenas aquelas necessárias para esclarecer o argumento do trabalho e sustentá-lo. Usar gráficos como alternativa a tabelas com muitas entradas e não duplicar dados em gráficos e tabelas. Evitar o uso de termos não técnicos em estatística, como "aleatório" (que implicaria em uma seleção ao azar), "normal", "significativo", "correlação" e "amostra", se não for em sentido estritamente técnico. Definir os termos estatísticos, abreviaturas e símbolos.

\section{Resultados}

Apresentar os resultados em uma seqüência lógica no texto, tabelas e figuras. Não repetir no texto todos os dados das tabelas ou ilustrações; enfatizar ou resumir somente as observações relevantes.

\section{Discussão}

Destacar os aspectos novos e importantes do estudo, assim como as conclusões dele derivadas. Evitar repetir de forma detalhada informações ou outro material apresentados na Introdução ou Resultados. Incluir na seção Discussão as implicações dos achados e suas limitações, mencionando envolvimento com futura pesquisa. Relacionar as observações com outros estudos relevantes.

Vincular as conclusões aos objetivos do estudo evitando-se fazer afirmações não qualificadas e conclusões que não forem plenamente respaldadas pelos dados. Os autores devem evitar, em particular, fazer declarações sobre os benefícios econômicos e gastos, a menos que seu manuscrito inclua informações e análises econômicas.

Evitar menção a qualquer trabalho que ainda não esteja concluído.

Estabelecer novas hipóteses apenas quando estiverem claramente justificadas.

Quando for conveniente incluir recomendações. 


\section{Agradecimentos}

Em um lugar apropriado do artigo (em nota de rodapé na página de idenficação ou em um apêndice; consultar as normas de cada revista) poderão ser incluídas uma ou várias declarações especificando:

a) colaborações de pessoas que merecem reconhecimento mas que não justificam sua inclusão como autor, como por exemplo o apoio de um chefe de departamento;

b) agradecimentos por auxílio técnico;

c) agradecimentos por apoio econômico e material, especificando a natureza do apoio;

d) relações que podem estabelecer conflito de interesses.

Mencionar pessoas que prestaram ajuda intelectual ao trabalho, mas cuja contribuição não justifica participar da autoria, descrevendo a contribuição como "assessoria científica", "revisão crítica do projeto de pesquisa", "coleta de dados" ou "participação no ensaio clínico". Estas pessoas devem expressar seu consentimento para ser mencionadas. Os autores são responsáveis pela obtenção de permissão, por escrito, das pessoas cujo nome constam dos agradecimentos, uma vez que os leitores podem inferir que endossam as informações e conclusões do trabalho.

Agradecer o apoio técnico em parágrafo separado daqueles destinados aos agradecimentos por outro tipo de contribuição.

\section{Referências}

Numerar as referências de forma consecutiva de acordo com a ordem em que forem mencionadas pela primeira vez no texto. Identificar as referências no texto, tabelas e legendas por números arábicos, entre parênteses. As referências, citadas somente em tabelas ou em legendas de figuras, devem ser numeradas de acordo com a seqüência estabelecida pela primeira identificação no texto de cada tabela ou figura.

Os exemplos seguintes estão baseados no formato usado pela National Library of Medicine, dos Estados Unidos, no Index Medicus. Os títulos de periódicos devem ser abreviados da forma como são apresentados no Index Medicus e podem ser consultados na "List of Journals Indexed", publicada anualmente com o número correspondente ao mês de janeiro do "Index Medicus". Esta lista também pode ser obtida através da Internet: http://www.nlm.nih.gov.

Evitar o uso de resumos como referências. Citações de trabalhos aprovados para publicação, mas ainda não publicados, deverão aparecer como "No prelo" ou “A ser publicado"; os autores deverão obter permissão, por escrito, para citar estes trabalhos, assim como certificar-se de que foram aceitos para publicação. Informações sobre trabalhos submetidos, mas não aceitos, devem ser citados no texto como "observações não publicadas", sempre com o consentimento, por escrito, dos responsáveis pela informação.

Evitar a citação de "comunicação pessoal" a menos que seja informação essencial e que não possa ser obtida em fontes impressas; em tal caso o nome da pessoa e a data em que se deu a comunicação deverão constar entre parênteses no texto. Para artigos científicos, os autores devem obter permissão e confirmação, por escrito, sobre a exatidão da fonte.

Os autores devem confrontar as referências com os documentos originais. Os "Requisitos Uniformes" (estilo Vancouver) baseiam-se em grande parte nas normas de estilo da American National Standards Institute (ANSI) adaptado pela NLM.

\section{Artigos de Periódicos}

\section{1 - Artigo padrão}

Incluir os 6 primeiros autores seguidos de et al. (Nota: A NLM inclui no máximo 25 autores; se existirem mais de 25 autores, listar os 24 primeiros e em seguida et al.).

Vega KJ, Pina I, Krevsky B. Heart transplantation is associated with an increased risk for pancreatobiliary disease. Ann Intern Med 1996 Jun 1; 124(11): 980-3.

Como opção, se a revista usa paginação contínua ao longo do volume (como faz a maioria das revistas) o mês e o número podem ser omitidos. (Nota: Por uma questão de consistência, esta opção é utilizada nos exemplos dos "Requisitos Uniformes". A NLM não utiliza esta opção).

Vega KJ, Pina I, Krevsky, B. Heart transplantation is associated with an increased risk for pancreatobiliary disease. Ann Intern Med 1996; 124: 980-3.

Mais de 6 autores:

Parkin DM, Clayton D, Black RJ, Masuyer E, Friedl HP, Ivanov E, et al. Childhood leukemia in Europe after Chernobyl: 5 years follow-up. Br J Cancer 1996; 73: 1006-12.

\section{2 - Instituição como autor}

The Cardiac Society of Australia and New Zealand. Clinical exercise stress testing. Safety and performance guidelines. Med J Aust 1996; 116: 41-2.

\section{3 - Sem indicação de autoria}

Cancer in South Africa /Editorial/. S Afr Med J 1994; 84: 15 .

\section{4 - Artigo em outro idioma}

(Nota: ANLM traduz o título para o inglês, colocao entre colchetes e adiciona uma indicação abreviada do idioma original). 
Ryder TE, Haukeland EA, Solhaug JH. Bilateral infrapatellar seneruptur hos tidligere frisk kvinne. Tidsskr Nor Laegeforen 1996; 116: 41-2.

\section{5 - Volume com suplemento}

Shen HM, Zhang QF. Risk assessment of nickel carcinogenicity and occupational lung cancer. Environ Health Perspect 1994; 102 Suppl 1: 275-82.

\section{6 - Fascículo com suplemento}

Payne DK, Sullivan MD, Massie MJ. Women“s psychological reactions to breast cancer. Semin Oncol 1996; 23(1 Suppl 2): 89-97.

\section{7 - Parte de um volume}

Ozben T, Nacitarhan S, Tuncer N. Plasma and urine sialic acid in non-insulin dependent diabetes mellitus. Ann Clin Biochem 1995; 32(Pt 3): 303-6.

\section{8 - Parte de um fascículo}

Poole GH, Mills SM. One hundred consecutive cases of flap lacerations of the leg in aging patients. $\mathrm{N} Z \mathrm{Z}$ Med $\mathrm{J}$ 1994; 107(986 Pt 1): 377-8.

\section{9 - Fascículo sem volume}

Turan I, Wredmark T, Fellander-Tsai L. Arthroscopic ankle arthrodesis in rheumatoid arthritis. Clin Orthop 1995; (320): 110-4.

\section{0 - Sem fascículo e sem volume}

Browell DA, Lennard TW. Immunologic status of the cancer patient and the effects of blood transfusion on antitumor responses. Curr Opin Gen Surg 1993; 325-33.

\section{1 - Paginação em números romanos}

Fisher GA, Sikic BL. Drug resistance in clinical oncology and hematology. Introduction. Hematol Oncol Clin North Am 1995 Apr; 9(2): xi-xii.

\section{2 - Indicação do tipo de artigo se necessário} Enzensberger W, Fisher PA. Metronome in Parkinson's disease [letter]. Lancet 1996; 347: 1337.

Clement J, De Bock R. Hematological complications of antavirus nephropathy (HVN) [abstract]. Kidney Int 1992; 42: 1285.

\section{3 - Artigo contendo retratação}

Garey CE, Schwarzman AL, Rise ML, Seyfried TN. Ceruloplasmin gene defect associated with epilepsy in the mice. [retractation of Garey CE, Schawarztman AL, Rise ML, Seyfried TN. In: Nat Genet 1994; 6: 42631]. Nat Genet 1995; 11: 104.

\section{4 - Artigo retratado}

Liou GI, Wang M, Matragoon S. Precocious IRBP gene expression during mouse development [retracted in Invest Ophthalmol Vis Sci 1994; 35: 3127]. Invest Ophthalmol Vis Sci 1994; 35: 1083-8.

\section{5 - Artigo com erratas publicadas}

Hamlin JA, Kahn AM. Herniography in simptomatic patients following inguinal hernia repair [published erratum appears in West J Med 1995; 62: 278]. West J Med 1995; 162-28-31.

\section{Livros e Outras Monografias}

\section{6 - Indivíduo como autor}

Ringsven MK, Bond D. Gerontology and leadership skills for nurses. $2^{\text {nd }}$ ed. Albany (NY): Delmar Publishers; 1996.

\section{7 - Editor, compilador como autor}

Norman IJ, Redfern SJ, editors. Mental health care for elderley people. New York: Churchill Livingstone; 1996.

\section{8 - Instituição como autor e publicador}

Institute of Medicine (US). Looking at the future of the Medicaid programme. Washington (DC): The Institute; 1992

\section{9 - Capítulo de livro}

Phillips SJ, Whiosnant JP. Hypertension and stroke. In: Laragh JH, Brenner BM, editors. Hypertension: pathophysiology, diagnosis, and management. $2^{\text {nd }}$ ed. New York: Raven Press; 1995. p.465-78.

\section{0 - Eventos (Anais de conferências)}

Kimura J; Shibasaki H., editors. Recent advances in clinical neurophysiology. Proceedings of the $10^{\text {th }}$ International Congress of EMG and Clinical Neurophysiology; 1995 Oct 15-19; Kyoto; Japan. Amsterdam: Elsevier; 1996.

\section{1 - Trabalho apresentado em evento}

Bengtson S, Solheim BG. Enforcement of data protection, privacy and security in medical informatics. In: Lun KC, Degoulet P, Piemme TE, Rienhoff O, editors. MEDINFO 92. Proceedings of the $7^{\text {th }}$ World Coangress on Medical Informatics; 1992 Sep 6-10; Geneva, Switzerland. Amsterdam: North Holland; 1992. p.1561-5.

\section{2 - Relatório científico ou técnico}

Publicado pela agência patrocinadora:

Smith P, Golladay K. Payment for durable medical equipment billed during skilled nursing facillity stays. Final report. Dallas (TX): Dept. of Health and Human Services (US), Office of Evaluation and Inspections; 1994 Oct. Report №: HHSIGOEI 69200860.

Publicado pela agência responsável por seu desenvolvimento:

Field MJ, Tranquada RE, Feaslley JC, editors. Health services research: work force and educational issues. Washington: National Academy Press; 1995. Contract №: AHCPR282942008. Sponsored by the Agency for Health Care Policy and Research.

\section{3 - Dissertação e tese}

Kaplan SJ. Post-hospital home health care: the elderley's access and utilization [dissertation]. St. Louis (MO): Wahington Univ.; 1995.

\section{4 - Patente}

Larsen CE, Trip R, Johnson CR, inventors; Novoste Corporation, assignee. Methods for procedures related to the electrophysiology of the heart. US patent 5,529,067. 1995 Jun 25. 


\section{Outros Trabalhos Publicados}

\section{5 - Artigo de jornal}

Lee G. Hospitalizations tied to ozone pollution: study estimates 50,000 admissions annually. The Washington Post 1996 Jun 21; Sect. A: 3 (col. 5).

\section{6 - Material audiovisual}

HIV+/AIDS: the facts and the future [videocassete]. St. Louis (MO): Mosby-Year Book; 1995.

\section{7 - Documentos legais}

Leis aprovadas:

Preventive Health Ammendments of 1993, Pub. L. N ${ }^{\circ}$ 103-183, 107 Stat. 2226 (Dec. 14, 1993).

Projetos de lei:

Medical Records Confidentiality Act of 1995, S.1360, $104^{\text {th }}$ Cong., $1^{\text {st }}$ Sess. (1995).

Código de regulamentações federais:

Informed consent. 42 C.F.R. Sect. 441.257 (1995).

Audiência:

Increased Drug Abuse: the Impact on the Nation's Emergency Rooms: Hearings Before the Subcomm. On Human Resources and Intergovernmental Relations of the House Comm. On Government Operations, 103 ${ }^{\text {rd }}$ Congr., $1^{\text {st }}$ Sess. (May 26, 1993).

28 - Mapa

North Carolina. Tuberculosis rates per 10,000 population, 1990 [demographic map]. Raleigh: North Carolina Dept. of Environment, Health, and Natural Resouces, Div. of Epidemiology; 1991.

\section{9 - Texto da Bíblia}

The Holy Bible. King James version. Grand Rapids (MI): Zondervan Publishing House; 1995. Ruth 3: 1-18.

30 - Dicionários e obras de referência similares

Steadman's medical dictionary. $26^{\text {th }}$ ed. Baltimore: Williams \& Wilkins; 1995. Apraxia; p.119-20.

\section{1- Obras clássicas}

The Winter's Tale: act 5, scene 1. Lines 13-16. The complete works of Williams Shakespeare. London: Rex; 1973.

\section{Material não Publicado}

\section{2- No prelo}

(Nota: A NLM prefere "forthcomming" uma vez que nem todos os tópicos serão impressos).

Leshner AI. Molecular mechanisms of cacaine addiction. N Engl J Med. In press 1996.

\section{Material Eletrônico}

\section{3 - Artigo de revista em formato eletrônico}

Morse SS. Factors in the emergence of infectious diseases. Emerg Infect Dis [serial online] 1995 Jan-Mar [cited 1996 Jun 5];1(1):[24 screens]. Available from: URL:http://www.cdc.gov/ncidod/EID/eid.htm

\section{4 - Monografia em formato eletrônico}

CDI, clinical dermatology illustrated [monograph on CD-ROM]. Reeves JRT, Maibach H. CMEA Multimedia Group, producers. $2^{\text {nd }}$ ed. Version 2.0. San Diego: CMEA; 1995.

\section{5 - Programa de computador}

Hemodynamics III: the ups and downs of hemody-namics [computer program]. Version 2.2. Orlando (FL): Computerized Educational Systems; 1993.

\section{Tabelas}

Após digitação, imprimir cada tabela em espaço duplo e em folhas separadas. Numerá-las consecutivamente segundo a ordem em que aparecem pela primeira vez no texto, atribuindo a cada uma um título breve. Dar a cada coluna um cabeçalho curto. Colocar as notas explicativas no rodapé da tabela $\mathrm{e}$ não no cabeçalho ou título, esclarecendo todas as abreviaturas não convencionais usadas. Para estas notas usar os seguintes símbolos, na seguinte ordem: $*,+, \S, * *,++, \S \S$, etc. e assim sucessivamente.

Identificar as medidas estatísticas de dispersão tais como desvio-padrão e média-padrão de erro.

Não traçar linhas internas horizontais ou verticais nas tabelas. Mencionar cada tabela no texto.

Se usar informações de outra fonte, publicada ou não, é preciso obter permissão e agradecê-las.

Se houver muitas tabelas poderão surgir problemas em sua distribuição nas páginas em relação à extensão do texto. Devem ser estudados alguns exemplares da revista a qual está sendo enviado o trabalho, com o objetivo de calcular quantas tabelas podem ser incluídas por cada 1.000 palavras do texto.

O editor da revista, ao aceitar o trabalho, pode recomendar que as tabelas adicionais, com informações de apoio relevante, mas demasiado amplas para publicação, sejam colocadas à disposição pelos autores. Neste caso, uma informação apropriada deve ser adicionada ao texto. De toda forma, estas tabelas deverão ser submetidas e avaliadas juntamente com o trabalho.

\section{Ilustrações (Figuras)}

Apresentar o número necessário de conjuntos completos de figuras. Estas deverão estar desenhadas e fotografadas por profissionais; não se admitindo o desenho à mão livre ou legenda datilografada. No lugar de desenhos originais, filmes de raios $\mathrm{X}$ e outros tipos de materiais, é necessário enviar fotografias 
nítidas, em branco e preto e reveladas em papel acetinado, normalmente em 127x 178mm (5x7 polegadas), mas nunca maiores que $203 \times 254 \mathrm{~mm}$ ( $8 \times 10$ polegadas). As letras, números e símbolos devem ser claros e uniformes ao longo de todo o trabalho e em tamanho adequado para que sejam legíveis quando reduzidos para publicação. Incluir os títulos e explicações detalhadas nas legendas das figuras e não nas próprias figuras.

Cada figura deverá ter uma etiqueta colada no verso indicando o número da mesma no texto, o número do autor e qual é a sua parte superior. Não escrever diretamente no verso da figura, nem utilizar clips que possam danificá-las ou rasgá-las. Tampouco as dobre ou as monte sobre cartolina.

As fotografias feitas através de microscópio devem conter indicadores internos de escala. Os símbolos, flechas ou letras usados em fotomicrografias devem contrastar claramente com o fundo.

Se forem usadas fotografias de pacientes, estes não podem ser identificados ou então suas fotos devem vir acompanhadas de permissão, por escrito, para serem divulgadas (veja Proteção aos Direitos e Privacidade dos Pacientes).

As figuras devem ser numeradas consecutivamente de acordo com a ordem em que foram citadas pela primeira vez no texto. Se uma figura já foi publicada, mencionar a fonte original e enviar permissão por escrito do detentor dos direitos autorais para a sua reprodução. Exceção é feita para documentos de domínio público.

Para as figuras em cores, certificar-se se a revista pede negativos em cores, diapositivos ou cópias em papel. Poderá ser útil ao editor receber desenhos suplementares indicando a área a ser reproduzida. Algumas revistas só publicam figuras em cores se o autor arcar com o custo extra que elas exigem.

\section{Legendas para Ilustrações}

Datilografar ou imprimir as legendas para ilustrações usando espaço duplo, em páginas separadas, com números arábicos correspondentes à figura. Quando os símbolos, flechas, números ou letras são usados para identificar uma ou várias partes das figuras, identificar e esclarecer o significado de cada uma com clareza na legenda. Explicar a escala interna e identificar o método de corantes usado nas fotomicrografias.

\section{Unidades de Medidas}

Medidas de comprimento, altura, peso e volume devem ser expressas em unidades métricas (metros, quilogramas ou litros, ou seus múltiplos decimais).

As temperaturas devem ser dadas em graus Celsius. A pressão sangüínea em milímetros de mercúrio.

Todos os valores hematológicos ou bioquímicos devem ser apresentados em unidades do sistema métrico decimal de acordo com o Sistema Internacional de Medidas (SI). Os editores podem pedir aos autores que sejam adicionadas unidades alternativas ou não pertencentes ao SI antes da publicação.

\section{Abreviaturas e Símbolos}

Utilizar só abreviaturas padrão, evitando inclúi-las no título e no resumo. O termo completo deve preceder a abreviatura quando ela for empregada pela primeira vez, salvo se forem unidades comuns de medida.

\section{Remessa do Manuscrito para a Revista}

Enviar o número necessário de cópias do manuscrito em envelope resistente, protegendo as fotografias e figuras com uma cartolina, para evitar que se dobrem.

Colocar as fotografias e transparências em um envelope separado.

Os manuscritos devem ser acompanhados de uma carta de apresentação assinada pelos autores, que deve incluir:

1. Informação sobre qualquer publicação prévia ou duplicada, ou submissão de qualquer parte do trabalho a outra revista ou meio de difusão, como definido anteriormente neste documento.

2. Uma declaração sobre aspectos financeiros ou de qualquer outro tipo que possa levar a um conflito de interesses.

3. Uma declaração de que o manuscrito foi lido e aprovado por todos os autores, que os requisitos para autoria, como estabelecido anteriormente este documento, foram cumpridos; e que os autores acreditam que o manuscrito representa um trabalho honesto.

4. Nome, endereço e número de telefone do autor que se responsabiliza pela comunicação aos demais sobre a revisão e aprovação final das provas de impressão.

Esta carta deve fornecer todas as informações adicionais que podem auxiliar o editor, tal como 
o tipo de artigo que o manuscrito representa para a revista em particular e se os autores estariam dispostos a custear a reprodução das figuras coloridas.

O manuscrito deve ser acompanhado por cópias com permissões obtidas para reproduzir material já publicado, para usar ilustrações ou informações sobre pessoas identificáveis, ou para mencionar pessoas por suas contribuições.

\section{Citação dos Requisitos Uniformes}

Os "Requisitos Uniformes para Manuscritos Apresentados a Revistas Biomédicas" e as informações que o acompanham estão publicadas em revistas do mundo todo e agora também em diferentes páginas da WEB. Para citar a versão mais recente dos "Requisitos Uniformes", devese assegurar de que seja a versão publicada em $1^{\circ}$ de janeiro de 1997 ou posteriormente a esta data. 